\title{
Comparative Study on Dacryocystorhinostomy (DCR) Surgery with Silicone Tube Intubation and Without Silicone Tube Intubation at Geta Eye Hospital
}

\author{
Ravi Dhar Bhandari*, Suresh Raj Pant, Bidya Prasad Pant and Ramesh Chandra Bhatta \\ Geta Eye Hospital, Kailali, Nepal
}

*Corresponding author: Ravi Dhar Bhandari, Geta Eye Hospital, Kailali, Dhangadhi, Nepal, Tel: 9848412968; E-mail: drravi_np@hotmail.com

Received: 10 Oct, 2018 | Accepted: 29 Dec, 2018 | Published: 05 Jan, 2019

Citation: Bhandari RD, Pant SR, Prasad BP, Bhatta RC (2019) Comparative Study on Dacryocystorhinostomy (DCR) Surgery with Silicone Tube Intubation and Without Silicone Tube Intubation at Geta Eye Hospital. J Ophthalmic Stud 2(1): dx.doi.org/10.16966/2639-152X.113

Copyright: (C) 2019 Bhandari RD, et al. This is an open-access article distributed under the terms of the Creative Commons Attribution License, which permits unrestricted use, distribution, and reproduction in any medium, provided the original author and source are credited.

\section{Abstract}

Aim and Objective: To compare the outcome of dacryocystorhinostomy surgery with silicone tube intubation and without silicone tube intubation at Geta Eye Hospital.

Methods: A hospital based retrospective comparative case study in which 87 subjects operated for dacryocystitis were analyzed, of which 49 were with silicone tube intubation and 38 were without silicone tube intubation. Study data were obtained from hospital records in which subjects were followed up on one week, one and half month and three months postoperatively.

Results: On three months of surgery 72 of $87(82.76 \%)$ were followed up, 39 with silicone tube $35(89.7 \%)$ had patent ducts and of 33 without silicone tube $29(87.9 \%)$ had patent ducts on lacrimal syringing which was considered as success of the surgery. Only 4 patients in each group $10.3 \%$ silicone tube and $12.1 \%$ without silicone tube had regurgitation of mucous or pus (failure) on lacrimal syringing. Both the group did not differ significantly $\mathrm{p}=0.54$.

Conclusion: Dacryocystorhinostomy with silicone tube intubation and without silicon tube intubation procedure offer similar efficient outcome.

Keywords: Dacryocystorhinostomy; Silicone tube intubation; Lacrimal syringing

\section{Introduction}

Chronic dacryocystitis is a chronic inflammation of the lacrimal sac, frequently caused by bacteria due to blockage of the nasolacrimal duct leading to constant and annoying epiphora [1].

This commonest external eye disease is always secondary to the obstruction in the Nasolacrimal Duct (NLD) and in a majority of cases the cause is obscured. Though it is not directly a blinding disorder, its complications like acute exacerbation, orbital cellulitis, corneal ulcer and even panophthalmitis may lead to blindness [2].

Untreated, dacryocystitis is capable of progressing to a vision or life-threatening condition, because the infection may evolve to preseptal cellulitis, orbital cellulitis, meningitis, and even cavernous sinus thrombosis and death [3].

The outcome of external DCR surgery can be measured by both anatomical and functional indicators. However, functional outcome is what matters to patients. It is being increasingly recognized that anatomic patency does not always translate into good functional outcome. Some patients with an anatomically patent nasolacrimal system still have epiphora symptoms. Hence, the functional outcome alone provides a good picture regarding DCR outcome [4].

Conventional (external approach) Dacryocystorhinostomy (DCR) is indicated for obstruction distal to the medial opening of the common canaliculus, and consists of anastomosis of the lacrimal sac to the mucosa of the middle nasal meatus. To increase the success rate of surgery the causes of failure must be find out [5].

External or endoscopic Dacryocystorhinostomy (DCR) is the standard treatment for Nasolacrimal Duct Obstruction (NLDO), with or without a previous history of dacryocystitis. The procedure gained popularity due to its efficacy and relatively low rate of complications. The external approach is made through a skin incision near the lacrimal sac and the endoscopic approach is made through the nasal cavity with the aid of a nasal endoscope [6].

A comparative study on DCR surgery with and without intraoperative use of Mitomycin C shows $4 \%$ vs $16 \%$ failure of DCR surgery [7]. 
Allen, et al. [8] identified a statistically significant rise in the failure rate of primary DCR with $v s$ without silicone intubation of the nasolacrimal system in 242 consecutive DCR surgeries (14.5\% vs $5.0 \%$, respectively) in 1989. Later in 1994, Walland and Rose reviewed 388 DCR cases and found no significant difference in failure rates for primary or repeated surgeries among subjects with and without silicone intubation [9].

Similar study done at Tilganga Institute of Ophthalmology found success rate at 6 months was $90 \%$ for DCR with intubation and $87 \%$ for DCR without intubation. There was no statistically significant difference between the two groups $(\mathrm{p}=0.77)$. But silicone tubes increased surgical cost by $20 \%$ [10].

This study was designed to compare the significant difference in outcome of DCR surgery with silicone tube intubation and without silicone tube intubation.

\section{Materials and Methods}

A hospital based retrospective comparative study conducted at Geta Eye Hospital, Kailali, Nepal. Performa designed for this study was used to record the relevant demographic information, history, clinical finding, surgical procedures and post-operative out come on one week, one and half month and 3 months follow-up from hospital records. Duct patency by syringing with normal saline will be considered as success of the surgery in both procedures.

Surgery records of 87 subjects performed dacryocystorhinostomy surgery for chronic dacryocystitis, of which 49 patients with silicone tube intubation and 38 without silicone tube intubation from July 1, 2012 to June 30, 2013 at Geta Eye Hospital were selected using following inclusion and exclusion criteria.

\section{Procedure}

Surgical technique: Two Surgeons were involved in DCR surgery, one of them operated with silicon tube and other operated without silicon tube. A standard external DCR procedure was performed under local anesthesia in all the cases. The nasal cavity of the operative side was packed with $4 \%$ lignocaine solution with adrinline soaked ribbon guage, and $2 \%$ lidocaine with 1:100,000 epinephrine was injected subcutaneously in the medial canthal area.

The skin was then incised and blunt dissection was performed until the periosteum of the frontal process of the maxilla was identified. A periosteal elevator was used to elevate the periosteum over the anterior lacrimal crest and into the lacrimal sac fossa, elevating the lacrimal sac and exposing the lacrimal bone. A Kerrison bone punch was used to create an osteotomy of approximately 1 to $1.5 \mathrm{~cm}$ in diameter on the lacrimal bone. The nasal mucosa was incised and anterior flaps were created. Lacrimal sac was incised and anterior flap was made. Insertion of bicanalicular, silicone stents (salastic tube) was performed. The silicone stents ends were passed through the nose. The anterior nasal mucosal flaps and lacrimal sac flaps were sutured with 4-0 vicryl suture. The salastic tubes were then passed through a silicone sponge segment to serve as an intranasal bolster and the tube was tied and the remaining end was cut short so that the tube did not prolapsed out of nose. The incision was closed in two layers, inner layer of the orbicularis muscle was sutured with a 4.0 chromic catgut suture, and the skin was sutured with a 6-0 prolene suture in an interrupted way.

\section{Postoperative course}

All patients were prescribed an oral antibiotic to be taken 4 times daily for 5 days after surgery (Ampiclox $500 \mathrm{mg}$ and ibuprofen $400 \mathrm{mg}$ three times a day). Local ciprofloxacin and dexamethasone eye drops four times a day for three weeks was prescribed as well Ciprofloxacin ophthalmic ointment was applied to the skin incision 2 times per day until 2 weeks. Patients were seen at 1 week, 6 weeks and 12 weeks after surgery. Skin sutures were removed on 1 week follow-up and silicone stents were removed at 6 weeks follow-up appointment. Surgical success was defined by patency of lacrimal passage by syringing. Surgical failure was defined as persistence or recurrence of dacryocystitis or epiphora and regurgitation of fluid on syringing of the naso-lacrimal passage.

\section{Inclusion and exclusion criteria}

The study has included dacryocystorhinostomy surgeries performed during above period at Geta Eye hospital. The study excluded post DCR failure due to trauma, infections, patient operated for second or more times for DCR, patients who did not attended for follow-up on one week and 1.5 months, chronic dacryocystitis caused by trauma and other ocular co-morbidities which affect outcome of the surgery.

\section{Data collection and analysis}

Patient records of all DCR surgeries with and without silicone tube intubation during the period from July 1, 2012 to June 30, 2013 at Geta Eye Hospital with given inclusion and exclusion criteria were included in this study. Data were analyzed statistically using epi-info 2008 version 3.5.1 to compare the outcome of the surgery. A value of $p<0.05$ was considered as statistically significant difference.

\section{Results}

A total of 87 patients were included in the study applying given inclusion and exclusion criteria, of which $30(34.5 \%)$ were males and $57(65.5 \%)$ were females which indicates the condition was more common in females. Mean age of the male patients was 33.2 years and female was 32.2 years.

DCR with silicone tube intubation were 49 (56.3\%) and without silicone tube intubation were 38 (43.7\%). Mean age of patients with silicone tube intubation was 32.47 ranged from 20 to 48 years and without silicone tube 32.59 ranged from 21 to 45 years. Both the group did not differ significantly on age ( $\mathrm{p}=0.95)$ (Figure 1$)$.

Preoperatively of 87 patients $44(50.6 \%)$ had mucous discharge, 32 (36.8\%) had pus discharge and $11(12.6 \%)$ had watery discharge on syringing. All 87 patients were operated under local anesthesia. On one and half months postoperative follow-up all 87 patients of which 49 patients with silicone tube intubation and 38 without silicone tube intubation had patent ducts on lacrimal syringing.

On three months of surgery 72 of $87(82.76 \%)$ were followed up, of which 39 of $49(79.6 \%)$ were with silicone tube intubation and 33 of 38 (86.8\%) were without silicone tube intubation. Of 39 patients with silicone tube group $35(89.7 \%)$ had patent ducts and of 33 patients without silicone tube group 29 (87.9\%) had patent ducts on lacrimal syringing which was considered as success of the surgery. Only 4 patients in each group $10.3 \%$ in silicone tube and $12.1 \%$ in without silicone tube group had regurgitation of mucous or pus (failure) on lacrimal syringing. Both the group did not differ significantly $\mathrm{p}=0.54$ (Table 1) (Figure 2).

\section{Discussion}

We evaluated 87 patients who underwent dacryocystorhinostomy surgery for chronic dacryocystitis, of which 49 patients with silicone tube intubation and 38 without silicone tube intubation. A total of which $30(34.5 \%)$ were males and $57(65.5 \%)$ were females. 


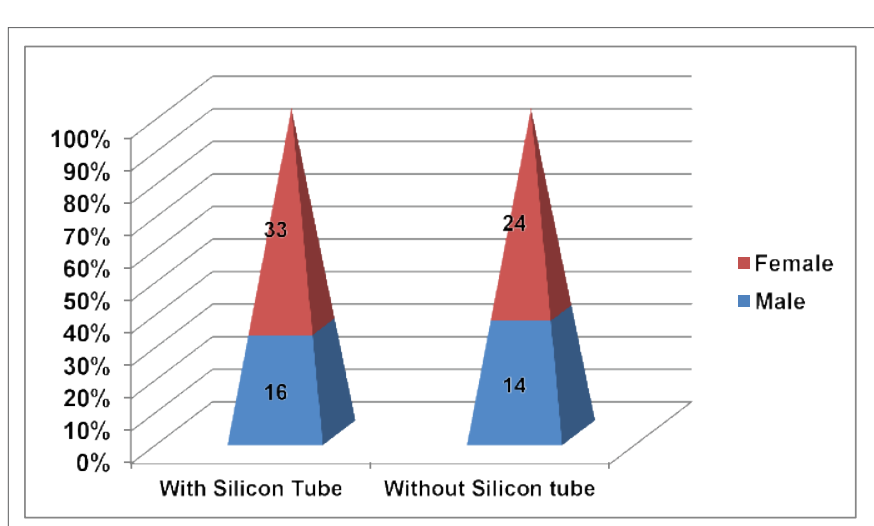

Figure 1: Graph showing DCR with silicon tube and without silicon tube with males and females.

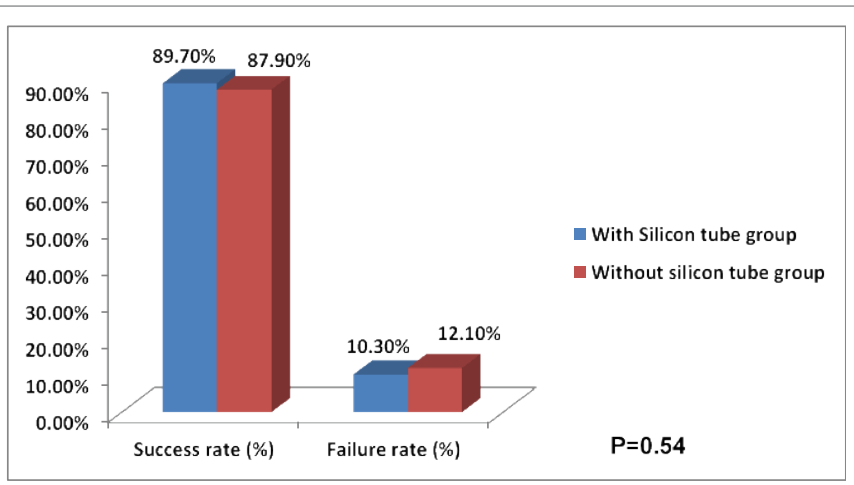

Figure 2: Comparison of success rate of DCR surgery with and without silicone tube intubation.

Our study dacryocystitis was more common in females (65.5\%) compare to males $(35.5 \%)$ in the study which was comparable with previous studies but the mean age and age range of the both group did not differ significantly. Similarly mean age and age range of the silicone tube intubation and without silicone tube intubation group did not differ significantly.

Out of total 60 study patient, 45 cases (75\%) were female and 15 cases $(25 \%)$ were male. The mean age in one group (conventional) $38.83 \pm 9.92$ years and in MMC group is $35.73 \pm 12.58$ years [11]

The mean age of patients with silicone tube intubation was 32.47 years and ranged from 20 to 48 years. The mean age of patients without silicone tube intubation was 32.59 years and ranged from 21 to 45 years. Both groups did not differ significantly on age $(\mathrm{p}=0.95)$.

On six weeks postoperatively 87 operated patients were followed up of which 49 were with silicone tube and 38 were without silicone tube intubation. On three months of surgery 72 of $87(82.76 \%)$ were followed up, of which 39 of $49(79.6 \%)$ were with silicone tube intubation and 33 of 38 (86.8\%) were without silicone tube intubation.

Postoperatively patient with silicone tube group 35 of 39 (89.7\%) had patent ducts and without silicone tube group 29 of 33 (87.9\%) patients had patent ducts on lacrimal syringing which was considered as success of the surgery.

Pandya, et al., [12] in a retrospective study, reviewed 338 external DCR surgeries and found that silicone intubation for longer than 6 months increased the success rate of the procedure [12].
Table 1: Compare on success rate of DCR surgery with silicone tube and without silicone tube groups.

\begin{tabular}{|l|c|c|c|c|}
\hline \multirow{2}{*}{$\begin{array}{l}\text { Patient } \\
\text { Groups }\end{array}$} & Total & $\begin{array}{c}1.5 \text { Months } \\
\text { follow up }\end{array}$ & \multicolumn{2}{|c|}{ 3 Months follow up } \\
\cline { 2 - 5 } & $\mathbf{N}=87$ & $\mathbf{N = 8 7}$ & \multicolumn{2}{|c|}{$\mathbf{N = 7 2}$} \\
\cline { 2 - 5 } & & Success Rate & $\begin{array}{c}\text { Success } \\
\text { Rate }\end{array}$ & Failure Rate \\
\cline { 2 - 5 } & No (\%) & No (\%) & No (\%) \\
\hline $\begin{array}{l}\text { With Silicone } \\
\text { tube group }\end{array}$ & 49 & $49(100 \%)$ & $35(89.7 \%)$ & $4(10.3 \%)$ \\
\hline $\begin{array}{l}\text { Without } \\
\text { Silicone tube } \\
\text { group }\end{array}$ & 38 & $38(100 \%)$ & $29(87.9 \%)$ & $4(12.1 \%)$ \\
\hline
\end{tabular}

P Value 0.54

Recently, a randomized clinical trial on the outcomes of external DCR with and without silastic intubation in 100 patients with uncomplicated primary Nasolacrimal Duct Obstruction (NLDO) showed that the six-month subjective and anatomic success rates were not significantly different between the intubated and non-intubated groups ( $90 \%$ vs $87 \%$ respectively) [13].

Rizvi SA, et al., [14] included patients of traumatic dacryocystitis and failed dacryocystorhinostomy in their study and came to a result that Silicone Intubation is one of the most effective modality in dealing with such cases.

Both the surgical procedures offer comparable good success rate on one and half month and three months follow-up. There was no statistically significant difference on outcome of the surgical procedures which was similar to the study done by Walland, et al., [9] and by Tilganga Institute of Ophthalmology [10].

Only 4 patients in each group $10.3 \%$ in silicone tube and $12.1 \%$ in without silicon tube group had regurgitation of mucous or pus (failure) on lacrimal syringing.

A Comparative study on DCR surgery done with and without intraoperative use of Mitomycin C showed by the end of 6 months of follow-up, $96 \%$ of patients were asymptomatic in the Mitomycin C group whereas $80 \%$ patients in the conventional group were asymptomatic. On lacrimal syringing 24 (96\%) eyes had patent passage in the Mitomycin C group where as only 1 (4\%) patient had complete block with regurgitation of mucopurulent fluid. In the conventional group 20 (80\%) eyes had patent passage, 4 (16\%) eyes had complete block with regurgitation of mucopurulent fluid and 1 (4\%) eye had partially patent passage on lacrimal syringing. Intraoperative and postoperative complications in both the groups were identical [7].

Allen, et al. [8] showed that there was a statistically significant rise in the failure rate of primary DCR with versus without silicone intubation of the nasolacrimal system in 242 consecutive DCR surgeries $(14.5 \%$ versus $5.0 \%$, respectively).

Lacune of our study was its retrospective manner. The information on the patients' diseases was taken from their medical charts, as well there was a significant loss of follow-up in our study. The follow-up of the patient was poor due poor economic status, lack of transport, difficult geographical terrain.

\section{Conclusion}

External dacryocystorhinostomy is a surgical procedure for 
chronic dacryocystitis which has good outcome for chronic dacryocystitis, which can be done with or without using silicone tube intubation.

Dacryocystorhinostomy with silicone tube intubation and without silicon tube intubation procedure offer similar efficient outcome on chronic dacryocystitis patients.

\section{References}

1. Rather S, Singh T (2013) Dacryocystorhinostomy with \& without silicon tube intubation in chronic dacryocystitis with nasolacrimal duct block. KK Science 15: 75-79.

2. Islam AKMR, Hossain KA, Rashid MA, Hossain MdA (2015) A Study of Conventional Dacryocystorhinostomy Operation without Silicon Tube Intubation in a Secondary Hospital. Faridpur Med Coll J 10: 2022.

3. Mauriello JA, Wasserman BA (1996) Acute dacryocystitis: an unusual cause of life-threatening orbital intraconal abscess with frozen globe. Ophthal Plast Reconstr Surg 12: 294-295.

4. Mansour K, Sere M, Oey AG, Bruin KJ, Blanksma LJ (2005) Longterm patient satisfaction of external dacryocystorhinostomy. Ophthalmologica 219: 97-100.

5. Selig YK, Biesman BS, Rebeiz EE (2000) Topical application of mitomycin-C in endoscopic dacryocystorhinostomy. Am J Rhinol 14: 205-207.

6. Sprekelsen MB, Barberán MT (1996) Endoscopic dacryocystorhinostomy: surgical technique and results. Laryngoscope 106: 187-189.
7. Qadir M, Ahangar A, Dar MA, Hamid S, Keng MQ (2014) Comparative study of dacryocystorhinostomy with and without intraoperative application of Mitomycin C. Saudi J Ophthalmol 28: 44-48.

8. Allen K, Berlin AJ (1989) Dacryocystorhinostomy failure: association with nasolacrimal silicone intubation. Ophthalmic Surg 20: 486-489.

9. Walland MJ, Rose JE (1994) The effect of silicone intubation on failure and infection rates after dacryocystorhinostomy. Ophthalmic Surg 25: 597-600

10. Saiju R, Morse LJ, Weinberg D, Shrestha MK, Ruit S (2009) Prospective randomised comparison of external dacryocystorhinostomy with and without silicone intubation. Br J Ophthalmol 93: 1220-1222.

11. Puzari BS, Pramod Kumar HN (2016) A comparative study on intraoperative mitomycin-c augmented external dacryocystorhinostomy with conventional dacryocystorhinostomy. Int J Res Med Sci 4: 3879-3883.

12. Pandya VB, Lee S, Benger R, Danks JJ, Kourt G, et al. (2010) External dacryocystorrhinostomy: assessing factors that influence outcome. Orbit 29: 291-297.

13. Choung HK, Khwarg SI (2007) Selective non-intubation of a silicone tube in external dacryocystorhinostomy. Acta Ophthalmol Scand 85: 329-332.

14. Rizvi SA, Sharma SC, Tripathy S, Sharma S (2011) Management of traumatic dacryocystitis and failed dacryocystorhinostomy using silicone lacrimal intubation set. Indian J Otolaryngol Head Neck Surg 63: 264-268. 